\title{
O DESPERDÍCIO DE ALIMENTOS E O IMPACTO FINANCEIRO OCORRIDO NO SETOR DE HORTIFRUTIGRANJEIRO DE UM ATACADISTA NA REGIÃO SUDESTE DO BRASIL
}

\author{
FOOD WASTE AND THE FINANCIAL IMPACT OF THE HORTICULTURAL \\ SECTOR FROM A WHOLESALER LOCATED IN BRAZIL SOUTHEAST
}

\author{
Ana Fernanda dos Santos Taketa \\ Sivanilza Teixeira Machado ${ }^{2}$
}

\section{RESUMO}

As mudanças nos sistemas produtivos, hábitos de consumo e distribuição dos alimentos permitiram diversos benefícios à sociedade contemporânea. Contudo, o surgimento de diversos problemas a serem enfrentados, dentre eles o desperdício e perdas dos alimentos ao longo da cadeia produtiva. O principal motivo desse transtorno é apontado pela má estrutura e falta de mapeamento da cadeia produtiva de alimentos, expondo a necessidade de planeamento e estratégias para mitigar as perdas e desperdícios em todos os elos da mesma. O trabalho tem como objetivo central identificar as principais causas dos desperdícios ocorridos no setor hortifrutigranjeiro de um atacadista localizado na região Sudeste do Brasil e o impacto nas perdas financeiras em relação a receita de vendas. Os resultados obtidos apontaram que o impacto financeiro dos desperdícios sobre vendas no setor foi de $3,5 \%$ e que a principal causa foi a deterioração dos alimentos, com $90 \%$ das ocorrências, evidenciando a necessidade de um melhor planejamento, maior controle na qualidade e tempo de vida dos produtos hortifrutigranjeiros nas prateleiras.

Palavras-chave: Atacadista. Deterioração. Hortifrutigranjeiro. Perdas financeiras.

\section{ABSTRACT}

Production systems, consumption habits evolution and food distribution allowed many benefits to actual Society. However, several problems have been emergerd and need to be faced, among them wastage and loss of food along the production chain. The reason for this disorder

\footnotetext{
1 Graduação em Logística pelo Instituto Federal de Educação, Ciência e Tecnologia, Campus Suzano. Participou do Programa Voluntário de Iniciação Científica e/ou Tecnológica (PIVICT). Com experiência na área de Engenharia de Produção e Logística. Participou do Programa de Bolsa de Iniciação Científica e/ou Tecnológica Institucional (PIBIFSP). E-mail : fernanda.afss@gmail.com

2 Possui graduação em Logística com ênfase em Transportes pela Faculdade de Tecnologia de São Paulo FATEC (2010) e graduação em Administração em Comércio Exterior - Faculdades Integradas Tibiriçá (2007). Cursou especialização em Marketing em Agronegócio pela Universidade Federal do Paraná UFPR (2012), mestrado em Engenharia Agrícola pela Universidade Federal da Grande Dourados - UFGD (2013) e doutorado em Engenharia de Produção pela Universidade Paulista (2016). Experiência profissional como Analista de Comércio Exterior e Logística Internacional. Atualmente é professora do Instituto Federal de Educação, Ciência e Tecnologia de São Paulo - campus Suzano. E-mail : sivanilzamachado@ifsp.edu.br
} 
is the poor structure and lack food production chain mapping, wich evidencing the necessity for planning and strategies to mitigate losses and wastage in all its links. This paper aims to identify the main causes of wastes in the horticultural industry of a wholesaler located in the Southeast region of Brazil and the impact on financial losses in relation to sales revenue. The results showed that the financial wastes impact on sales was $3.5 \%$ and that the main cause of the wastes was food deterioration, with $90 \%$ of occurrences, evidencing the necessity for better planning, quality and shelf-life of horticultural products.

Keywords: Wholesaler. Deterioration. Horticultural. Financial losses.

JEL: L66. L81. Q13.

\section{INTRODUÇÃO}

Com a expansão populacional e aumento da demanda por alimentos surge a necessidade de uma gestão mais eficientes no controle dos desperdícios de alimentos agrícolas, destacando o setor hortifrutigranjeiro, que apresenta alto volume de perdas devido à alta perecibilidade dos produtos (BELIK et al., 2012; PIGATTO, 2017). As perdas ocorridas na cadeia de alimentos (food chain), além do impacto social tem também forte influência na competitividade do setor em todos os elos da cadeia produtiva, pois representa redução da receita de vendas e aumento do preço de mercado.

Nesse sentido, uma visão sistemática da cadeia produtiva de alimentos é essencial para mitigar as perdas e desperdícios decorridos de falhas no processo de gerenciamento de abastecimento, distribuição e comercialização (LINS et al., 2017). Segundo a FAO/ONU, estima-se que ao longo da cadeia se perde $28 \%$ pelos consumidores, $28 \%$ na produção, $17 \%$ na venda e distribuição, $22 \%$ no manejo, armazenamento e transporte e $6 \%$ no processamento.

Os autores Oliveira, Lima-Filho e Watanabe (2013) reiteram que o sistema de distribuição de alimentos no país, atualmente, sofre com a falta de infraestrutura, pouco investimento tecnológico e um dos principais causadores de perdas e aumento do custo do produto ao consumidor final é a falta de mapeamento da cadeia produtiva. Segundo Castro e Jaime (2017), quando se trata de distribuição de alimentos perecíveis é importante observar toda a variação de qualidade e de perdas que ocorrem de maneira contínua desde o produtor até a mesa do consumidor final, impactando diretamente na lucratividade.

De certo modo, o aumento da competitividade no setor de distribuição de alimentos contribuiu para adoção de medidas estratégias para diminuir os custos logísticos e reformulações nos contratos dos varejistas com os fornecedores. Em meio as mudanças dos hábitos alimentares da população surgiu um novo tipo de comércio que se adaptava de maneira mais abrangente as flutuações de demanda, hábitos dos consumidores e critérios de qualidade e variabilidade de produtos, transformando também a forma de negociação e aquisição de produtos com os fornecedores, 0 chamado "atacarejo" (OLIVEIRA, LIMA-FILHO e WATANABE, 2013).

De acordo com Hsien (2012) o sistema de comercialização de produtos em atacado originou-se para vender em grandes quantidades para os varejistas e com isso permitir que o produtor obtivesse um maior alcance, com o decorrer do tempo e mudanças no fluxo de bens de consumo, o intermediário passou a atender também o consumidor final, que sentiu-se atraído pela variedade de produtos e, principalmente, 
pelo menor preço, pois o atacadista de autosserviço elimina intermediários e agentes facilitadores. Assim surgiu uma nova modalidade de distribuidor que atende tanto 0 consumidor final quanto o varejista e ainda possui uma enorme influência sobre seus fornecedores, pois atualmente domina o mercado de distribuição de alimentos.

Nesse sentido, o objetivo desse trabalho é analisar e discutir os desperdícios ocorridos em um atacadista da região sudeste do país, que se encontra nos elos finais da cadeia produtiva, visando identificar os principais fatores que induzem os desperdícios de alimentos no ponto de distribuição e o seu impacto financeiro no setor de hortifrutigranjeiro.

\section{REFERENCIAL TEÓRICO}

\section{A cadeia produtiva de hortifrutigranjeiro e a importância da agricultura familiar para o setor}

A produção de frutas e hortaliças tem crescido nos últimos anos devido ao desenvolvimento e uso de novas tecnologias nas diferentes fases da cadeia hortifrúti, produção, distribuição e comercialização. Em 2012/2013, a produção mundial de frutas cítricas foi de 119.164,4 mil toneladas, sendo o Brasil responsável por 15,5\% dessa produção (FAO, 2015). Quando se observa o processamento mundial de frutas cítricas, a produção em 2012/2013 foi de 25.333,4 mil toneladas, sendo o Brasil o maior beneficiador e exportador de frutas cítricas com 11.543,4 mil toneladas, isto representa mais de $45 \%$ da produção mundial e $96,5 \%$ da produção no hemisfério norte (FAO, 2015).

Em termos comparativos, em 2014, a produção brasileira das principais frutas (abacate, banana, laranja, limão, maça, mamão, manga, melões, morangos, peras e uvas) alcançou 31,32 milhões de toneladas distribuídos em 1,45 milhões de hectare, produtividade média de 21,54 toneladas/hectare, e a produção de olerícolas, tais como batata doce, batata, tomate, alho e vegetais em geral foi de 11,54 milhões de toneladas distribuídos em 0,47 milhão de hectare, produtividade média de 24,41 toneladas/hectare (FAO, 2014).

Para o mesmo período, a produção das principais culturas agrícolas no Brasil, soja, milho e cana de açúcar foi de 902,750 milhões de toneladas distribuídas em 56,12 milhões de hectare, ou seja, produtividade média de 16,08 toneladas/hectare (FAO, 2014). O mamão é a fruta com maior produtividade com aproximadamente 50 toneladas/hectare, enquanto 0 tomate apresenta aproximadamente 67 toneladas/hectare, sendo mais próximo da produtividade da cana de açúcar que chega a 70 toneladas/hectare (FAO, 2014). Além disso, a produtividade média de frutas e olerícolas (amplitude 8,44 $\sim 50,06$ toneladas/hectare) são superiores a produtividade de soja (2,87 toneladas/hectare) e milho (5,18 toneladas/hectare) (FAO, 2014). Dessa forma, comparando a produção de soja e milho com a produção hortifrúti, percebe-se a importância e o valor social e econômico da cadeia de hortifruti para o país e para o agronegócio brasileiro.

A evolução dos sistemas de produção tem modificado a base da sociedade e a forma de vida no globo. Considerando a evolução das cadeias produtivas, percebe-se que algumas cadeias são mais desenvolvidas do que outras. De acordo com Oliveira (2011), o que se conhece hoje nacionalmente sobre cadeias produtivas do agronegócio deriva das pesquisas de Davis e Goldberg, 1957 e do conceito de fillières, 
da literatura francesa que designa basicamente uma ferramenta administrativa de análise das partes das cadeias produtivas, que visa modelar as complexas relações das produções agrícolas, classificando de maneira geral os integrantes como produtores, processadores, atacadistas, distribuidores, prestadores de serviços, varejistas e consumidores.

De uma maneira mais ampla o termo fillière traz o sentido de fileira sendo vinculado a sequência de atividades empresariais que estão ligadas a transformação do produto, nesse contexto a cadeia agroindustrial é a soma e a sequência das atividades desempenhadas para constituir um produto advindo dos meios agrícolas (VIAL et al., 2009).

Além desses conceitos, pode-se pensar no conceito de complexo agroindustrial (CAI) que está ligado a uma matéria prima específica sendo sua arquitetura ditada por essa matéria base, sua formação está diretamente ligada a um conjunto de cadeias produtivas associadas a um produto ou família de produtos (OLIVEIRA, 2011).

A classificação das cadeias produtivas, na agricultura, enfrenta dificuldade devido à variedade dos produtos e seus processos produtivos, no setor hortifrúti o desafio aumenta devido ao fato da maior parte da produção nacional ser realizada por pequenos e médios produtores e a dificuldade aos acessos dos dados desses produtores e até a inexistência dos mesmos (CNA, 2017). A fruticultura, por exemplo, apresenta diversas peculiaridades na sua cadeia produtiva que a diferença das demais atividades da agricultura nacional, essas diferenças podem ser vistas como obstáculos ou como diferenciação para uma maior competitividade do segmento, quando devidamente trabalhadas. Dentro das especificidades pode-se destacar o número elevado de cooperativas e associações de produtos; flutuações acentuadas dos preços ligadas a sazonalidade e aos diferentes climas do país que impactam no calendário da produção; forte presença de agricultores familiares; a fidelização do cliente diretamente ligada a marca geralmente do varejista e não ao produto, problema também enfrentado na exportação; e falta de infraestrutura e dificuldade para se enquadrar nos padrões de qualidade para o comércio internacional (BUAINAIN; BATALHA, 2007).

Avanços no campo de estudos das relações empresariais, leva ao conceito mais recente e utilizados nas últimas duas décadas: a cadeia de suprimentos. De acordo com o CSCMP (Council of Supply Chain Management Professionals, 2018), a cadeia de suprimentos engloba desde o planejamento e gerenciamento de todas as atividades ao longo do canal de distribuição até a coordenação da colaboração entre todos os parceiros do respectivo canal de distribuição.

A agricultura familiar é responsável por cerca de $70 \%$ de todos os alimentos consumidos no país, adquirindo um papel decisivo na cadeia produtiva de alimentos como mandioca, feijão, milho, entre outros se encontra a produção de frutas e hortaliças (BRASIL, 2015). Entretanto a agricultura familiar, que ainda tem uma designação de agricultura de subsistência, não consegue sozinha se colocar no mercado, sendo necessária a ajuda de intermediadores, formação de cooperativas e associações rurais.

O papel das cooperativas e das associações agrícolas é facilitar as transações do pequeno produtor, ajudar com o escoamento da produção rural e garantir a sustentabilidade das propriedades rurais, assim como, uma padronização entre os produtos dos cooperados. Além disso, por ser uma produção fragmentada, cada família produz da sua maneira, não há uma padronização desses produtos. O setor possui destaque, com suas 1.597 instituições e 180,1 mil cooperados, responsável por $50 \%$ do PIB agrícola, estima-se que de tudo que é produzido no campo brasileiro 
$48 \%$ do volume passa pelas cooperativas de alguma forma (CREFITO, 2010; MAPA, 2016). Contudo, a falta de processos padronizados na produção e distribuição de alimentos tem contribuído para as perdas na cadeia produtiva.

Os diversos problemas ocorridos nas cadeias de alimentos estão ligados a história da formação dos sistemas agrícolas no Brasil, as políticas agrícolas, os grandes produtores agrícolas e a estrutura da agricultura familiar que sofreram grandes alterações devido as mudanças do ambiente socioeconômico e influência do mercado internacional. Uma recomendação para facilitar os estudos das cadeias produtivas e identificar fatores que afetam seu desempenho, para uma análise mais aprofundada é por meio da aplicação de um enfoque sistêmico, dividindo a cadeia em pequenos pontos para facilitar o estudo da mesma como um todo (ASSUNÇÃO; WANDER, 2014).

\section{A logística de perecíveis e as perdas no setor hortifrutigranjeiro}

De modo geral, estima-se que cerca de $30 \%$ dos alimentos produzidos no mundo são desperdiçados o corresponde aproximadamente 1,3 bilhão de toneladas (FAO/ONU, 2017). Como o índice é uma estimativa não se sabe o real valor dessas perdas e o impacto socioeconômico que elas têm na sociedade. Como exemplo, citase a logística da cadeia produtiva do ovo de mesa que vem tentando se adaptar à demanda do mercado interno e externo. Assim como outros elos da cadeia, tem caminhado de forma lenta, apesar do país estar entre os maiores produtores do mundo, os produtores avícolas ainda enfrentam dificuldades para se adequar às exigências do mercado, principalmente ligadas a qualidade.

Dentre os aspectos importantes para tornar mais eficiente a logística de perecíveis estão fatores ligados a qualidade e riscos que afetam diretamente 0 processo logístico como: climático na produção; com a alta perecibilidade no transporte; de falta de controle de mercadorias; de falta de mão de obra especializada; de infraestrutura de armazenagem; de manejo de mercadoria; de protestos e manifestações nas estradas; de roubo de mercadoria na distribuição; de sazonalidade; de variação na quantidade demandada; financeiro ou de crédito; financeiro ou de crédito; na produção; e no acondicionamento (LIMA et al., 2017; PIGATTO, 2017).

Estudos apontaram que a melhor prática logística era similar entre diferentes empresas, independentemente da posição no canal de distribuição, tamanho ou ramo de atividade (FIGUEIREDO, 2007). Segundo Lins et al. (2017) no setor hortifrúti, onde grande parte dos produtos se perdem por conta de avarias causando grande redução de lucratividade, a logística merece uma atenção especial por parte das organizações. Atualmente, os maiores problemas enfrentados na logística de alimentos está relacionado à alta perecibilidade e a inadequação dos veículos de transporte, que geralmente não são específicos para esse tipo de distribuição, como exemplo, cita-se o transporte de maçã e banana que geralmente realizados em carros particulares, impactando na qualidade da fruta que será comercializada (SELLA; SILVA, 2012; FOSCACHES et al., 2012; GLORIA; PRIOR; MARJOTTA-MAISTRO, 2015). Em relação aos problemas de transporte do setor, citam-se a temperatura e tempo de armazenamento, assim como na cadeia das frutas citadas anteriormente, pois os ovos "in natura" podem se deteriorar no prazo de 15 dias após a data de postura, se transportados e armazenados sem qualquer tipo de refrigeração, além de afetar as características organolépticas do produto, essenciais para o consumidor final (DONATO et al., 2009). 
As grandes perdas de alimentos mobilizaram grandes organizações como Organização das Nações Unidas (ONU), Fundo Monetário Internacional (FMI) e Banco Internacional para Reconstrução e Desenvolvimento (BIRD), a incentivar iniciativas de combate a esse problema em âmbito mundial, porém os esforços investidos ainda são pouco difundidos numa escala global, pois a eficiência produtiva se perde ao longo da cadeia quando as políticas agrícolas nacionais incentivam em sua maioria o aumento da produção bruta por hectare cultivado e não visam a oferta líquida dos alimentos para o consumidor final (BELIK et al., 2012). Visando adotar medidas que tem como objetivo acabar com a pobreza, proteger o meio ambiente, promover prosperidade e bem-estar para todos, entre outros, a ONU promoveu a Agenda 30 que engloba 17 ODS (Objetivos de Desenvolvimento Sustentável), entre eles se destaca o ODS12 - Consumo e produção sustentáveis, que visa diminuir as perdas e desperdício per capita de alimentos pela metade no mundo até o ano de 2030, tanto no varejo, quanto na cadeia produtiva, dando destaque para as perdas pós colheita (FAO/ONU, 2016).

Outra problemática recai sobre a integração entre os membros da cadeia produtiva de alimentos, que enquanto um elo vê o outro elo como adversário e não como um parceiro de negócios, pouco se ajustará na área da gestão da cadeia. A prática do comércio de repasse da perda financeira devido a sua gestão ineficiente para o bolso do consumidor começa a ser questionado. Consumidores mais conscientes estão cada vez mais exigentes e requerem transparência no processo produtivo e comercialização dos alimentos.

Conceituando a perda (losses) de alimentos deriva da ineficiência na cadeia de suprimentos de alimentos, como exemplo, cita-se as primeiras fases da cadeia produtiva que engloba a pós colheita, armazenamento, transporte e produção; 0 conceito de desperdício (waste) está atrelado ao descarte de produtos que ainda possuem valor e boas características para consumo no final da cadeia, considerando a distribuição e os hábitos alimentares individuais dos consumidores; e o desperdício geral (wastage) de alimentos se refere ao somatório das perdas e desperdícios gerados pela cadeia como um todo (FOODDRINK EUROPE, 2018).

De acordo com Belik et al. (2012) no setor hortifrúti a perda se destaca devido à alta perecibilidade desses alimentos deixando nítida a necessidade de meios estratégicos que possam mitigar os índices de perdas. O Brasil é um grande produtor de frutas e hortaliças. Segundo a Empresa Brasileira de Pesquisa Agropecuária (EMBRAPA) foram produzidas cerca de 43,8 milhões de toneladas no setor no ano de 2016 (EMBRAPA, 2016). Entretanto, isto não significa que essa quantidade foi comercializada e devidamente consumida pelo mercado.

Diversas são as estratégias utilizadas pelas empresas de alimentos para reduzir as perdas e desperdícios, como aplicação das ferramentas tecnológicas no gerenciamento da cadeia produtiva. Entre as ferramentas utilizadas, a análise gerencial dos indicadores operacionais das lojas de atacado e varejo pode auxiliar na identificação dos principais problemas e na tomada de decisão para a busca de soluções viáveis.

\section{PROCEDIMENTOS METODOLÓGICOS}

Inicialmente realizou-se uma pesquisa sistemática da literatura, nas principais bases de pesquisa e tendo como referências materiais científicos e sites oficiais. 
Posterior, realizou-se um estudo de caso em um atacadista localizado na região Sudeste, Brasil.

Neste estudo investiga as perdas conhecidas pelo atacadista, analisando o banco de dados do setor de hortifrutigranjeiro, com dados sobre o volume de vendas e perdas operacionais (quebras), em valor monetário ( $R \$$, reais). O período analisado foi de janeiro a dezembro de 2017, com exceção do mês de agosto de 2017, devido a falha no sistema e os dados não confiáveis, preferiu-se a exclusão do mês da análise.

O banco de dados composto de 86 tipos de produtos do setor de hortifrutigranjeiro foi analisado e tratado, sendo reduzido para média aproximada de 72 produtos/mês. Foram desconsiderados da análise produtos misturados, tais como: agrega, kit yakissoba, kit sopa, salada mix, entre outros. No primeiro momento, o banco de dados foi analisado completo e, posterior, foi dividido em três grupos: Ifrutas, II-hortaliças e III-ovos, conforme Tabela 1. Para a divisão entre os alimentos, se utilizou das Normas de Classificação das Frutas e Hortaliças do Programa Brasileiro para a Modernização da Horticultura (CEAGESP, 2003), com a citação de algumas frutas já classificadas: abacaxi, banana, caqui, goiaba, laranja, limão, mamão, maracujá, etc.; e hortaliças: alface, batata, berinjela, cebola, pepino, pimentão, tomate, entre outros (CEAGESP, 2003).

Tabela 1 - Composição dos grupos de alimentos analisados

\begin{tabular}{|c|c|c|}
\hline Grupos & Descrição & Tipos de alimentos \\
\hline I-frutas & Frutas frescas & $\begin{array}{l}\text { Maça, Banana, Pêssego, Laranja, Abacaxi, } \\
\text { Melancia, Uva, Pera, Manga, Mamão, Limão, } \\
\text { Maracujá, Morango, Ameixa, Melão, Cereja, Lichia, } \\
\text { Abacate, entre outras }\end{array}$ \\
\hline II-hortaliças & $\begin{array}{l}\text { Raízes, tubérculos, vegetais } \\
\text { e verduras }\end{array}$ & $\begin{array}{l}\text { Tomate, Batata, Alface, Pimentão, Alho, } \\
\text { Abobrinha, Cenoura, Pepino, Cebola, Chuchu, } \\
\text { Couve, Rúcula, Berinjela, Vagem, Repolho, } \\
\text { Brócolis, Cheiro Verde, Cebolinha, Escarola, } \\
\text { Agrião, entre outros }\end{array}$ \\
\hline III-ovos & & Ovos de galinha \\
\hline
\end{tabular}

Fonte: Adaptado de CEAGESP (2003)

O objeto de estudo trata-se de uma rede atacadista que atua no estado de São Paulo há 17 anos, considerada de grande porte, conta com mais de 4 mil colaboradores em suas 34 filiais, classificado como atacadista de autosserviço que tem o apelo de preço baixo para garantir o alto consumo de produtos e o pagamento das compras é geralmente feito a vista. O estudo de caso estudou as variáveis de perdas conhecidas ocorridas no setor hortifrutigranjeiro de uma filial da rede atacadista, neste trabalho denominado XYZ. De acordo com Sebrae (2019), dentre os indicadores operacionais, as perdas têm como objetivo medir as perdas com base nas quebras ocorridas, furtos e perecibilidade, sendo a recomendação de cálculo em porcentagem, Equação 1:

$$
\text { Indicador de Perdas }=\left(\frac{\text { Itens perdidos }}{\text { Total de itens }}\right) \times 100
$$

Para a realização do cálculo, o setor deve considerar como fonte de dados, o inventário realizado na loja, podendo ser periodicidade anual e a polaridade deve ser o quanto menor o índice, melhor é o indicador de perdas (SEBRAE, 2019). Neste 
estudo, a Equação 1 foi adaptada para valores monetários, considerando o valor perdido $(\mathrm{R} \$)$ em relação ao valor total dos itens analisados do setor hortifrutigranjeiro.

$O$ Banco de dados analisado do atacadista $X Y Z$, apresentava os seguintes indicadores de quebras conhecidas, Tabela 2

Tabela 2 - Variáveis de quebra conhecidas utilizadas no estudo

\begin{tabular}{|c|c|l|}
\hline Variáveis & Tipo de quebra & \multicolumn{1}{|c|}{ Descrição da ocorrência de quebra devido } \\
\hline CL & Cliente & ao manuseio do cliente \\
\hline EQ & Equipamento & ao uso de equipamentos, para movimentação no ponto de venda \\
\hline FC & Funcionário & ao manuseio/manipulação inadequada por funcionários \\
\hline FO & Fornecedor & $\begin{array}{l}\text { a procedimentos do fornecedor (frutas e hortaliças chegam no } \\
\text { ponto de venda em condiçães inadequadas, devido tipo de } \\
\text { embalagens, transporte e manuseio) }\end{array}$ \\
\hline TR & Degustação & a autorização de porcentagem destinada à degustação; \\
\hline DE & Transformação & $\begin{array}{l}\text { A destinação do produto para a transformação em produtos } \\
\text { processados, como tomate para produção do molho de tomate e } \\
\text { outros produtos de fabricação própria do atacadista; }\end{array}$ \\
\hline AU & Autorizada & $\begin{array}{l}\text { A presença de danos nos alimentos, por deterioração do produto } \\
\text { (ação microbiana); }\end{array}$ \\
\hline a autorização de descarte \\
\hline VE & Vencimento & $\begin{array}{l}\text { a falta de gerenciamento da data de validade do produto atribuída } \\
\text { pelo produtor/fornecedor. }\end{array}$ \\
\hline
\end{tabular}

Fonte: Autores (2019)

Para o cálculo das estimativas de perdas financeiras, os dados foram tabulados em planilha Excel e, posterior, foram processados os cálculos da estatística descritiva, tais como valores totais, médios e proporções. Além disso, foram gerados gráficos e análise de Pareto, para identificação dos principais produtos e tratamento dos desperdícios ocorridos no setor de hortifrutigranjeiro, comparando o grupo l-frutas com II/III-Hortaliças\&Ovos, uma vez que o grupo III é composto apenas por ovos, inviabilizando a análise de Pareto de forma isolada.

\section{RESULTADOS E DISCUSSÕES}

A investigação das causas de não conformidades, como os desperdícios, no setor de hortifrúti pode contribuir para melhoria dos processos e dos padrões de qualidade dos produtos.

\section{Perdas Financeiras Gerais}

No ambiente de varejo e atacado, entende-se por quebras operacionais as perdas identificadas (conhecidas), que representam as avarias causadas por manipulação e movimentação inadequada dos produtos e que reduzem o valor de comercialização; ou ainda, por vencimento de produtos e deterioração de perecíveis, que inviabilizam a comercialização dos produtos. Já as perdas não identificadas (desconhecidas), são aquelas ocorridas por falhas operacionais e que não permitem a identificação da causa, como exemplos, os furtos. Dessa forma, a análise das 
quebras operacionais conhecidas do setor de hortifrutigranjeiro do atacadista apresentou uma perda financeira de $\mathrm{R} \$ 3.893 .544,77 /$ ano, o que representa aproximadamente 3,5\% das vendas totais do setor. Observa-se que o mês de junho apresentou a maior proporção de perdas durante o ano $(23,37 \%)$, o que consequentemente, apresentou o maior índice de perdas sobre as vendas $(8,22 \%)$, Tabela 3. Neste estudo, os índices de perdas estão abaixo dos encontrados por Ruben, Boselie e Lu (2007), que identificaram perdas na cadeia acima de $20 \%$ do total de venda, devido muitos dos fornecedores não deterem instalações e transporte refrigerados para atender os requisitos da cadeia de hortifrúti.

Tabela 3 - Proporção de perdas financeiras do setor de hortifrutigranjeiros, por mês.

\begin{tabular}{lcccc}
\hline \multicolumn{1}{c}{ Mês } & $\mathbf{n}$ & Perdas (R\$) & $\begin{array}{c}\text { Proporção de } \\
\text { Perdas (\%) }\end{array}$ & $\begin{array}{c}\text { Índice de perdas sobre } \\
\text { vendas (\%) }\end{array}$ \\
\hline Janeiro & 76 & $266.322,94$ & 6,84 & 3,08 \\
Fevereiro & 72 & $259.807,17$ & 6,67 & 3,08 \\
Março & 72 & $312.531,02$ & 8,03 & 3,28 \\
Abril & 71 & $270.001,9$ & 6,93 & 2,51 \\
Maio & 70 & $328.143,41$ & 8,43 & 2,96 \\
Junho & 70 & $909.746,13$ & 23,37 & 8,22 \\
Julho & 71 & $242.358,06$ & 6,22 & 2,19 \\
Setembro & 70 & $297.964,3$ & 7,65 & 2,90 \\
Outubro & 71 & $287.766,52$ & 7,39 & 2,86 \\
Novembro & 70 & $274.824,98$ & 7,06 & 2,77 \\
Dezembro & 74 & $444.078,34$ & 11,41 & 3,58 \\
Ano & & $3.893 .544,77$ & 100 & 3,43 \\
\hline
\end{tabular}

Fonte: Autores (2018)

Quando analisado por grupo de produtos, observa-se que as hortaliças têm uma perda financeira de $\mathrm{R} \$ 1.960 .089,01$, o que representa $50,34 \%$ do valor das perdas financeiras totais, frutas apresentam perdas de $R \$ 1.388 .847,62(35,67 \%) \mathrm{e}$ ovos o valor de $\mathrm{R} \$ 544.608,14$ (13,99\%). Considerando que o valor da perda financeira abrange apenas o setor de hortifrutigranjeiro em uma das lojas da rede atacadista, e que existe uma padronização dos processos e operações da rede, podese estimar que a perda apresentada neste estudo é uma referência de análise para outras filiais. Assim, a busca por soluções para melhorar o indicador de quebras operacionais nesta filial, pode ser replicado para todas as demais da rede atacadista.

O consumidor consciente tem requerido produtos oriundos de sistemas produtivos sustentáveis, que se utilizam dos recursos naturais de forma consciente. $\mathrm{E}$ o desperdício de alimentos é uma prática não sustentável e que agride o meio ambiente e impacta negativamente no fator socioeconômico da agricultura familiar. A redução de desperdício de alimentos depende da conscientização da sociedade, abrangendo todos os setores da economia. Ações isoladas são realizadas, mas não são suficientes, como exemplo, o Banco de Alimentos criado em 2003 pela Companhia de Entrepostos e Armazéns Gerais de São Paulo (CEAGESP), com objetivo de coletar, selecionar e distribuir alimentos fora do padrão de comercialização oferecidos por produtores e comerciantes para entidades sociais; contudo ainda são desperdiçadas 150 toneladas de alimentos/dia (CEAGESP, 201-; REIS et al., 2015).

A Figura 1, apresenta as perdas financeiras distribuídas pelo período analisado, por grupo de produtos. 
Figura 1 - Distribuição das perdas financeiras ao longo do ano, por grupo de produto.

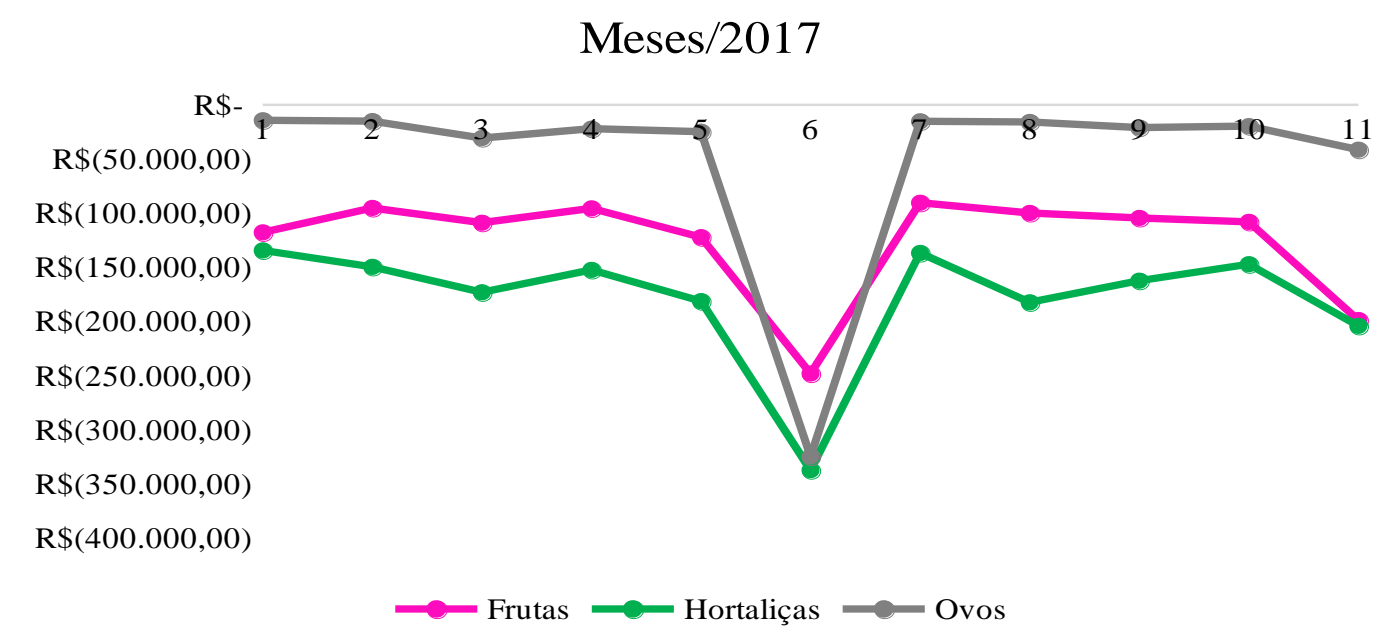

Fonte: Autores (2018)

A redução dos desperdícios no setor pode ocorrer se houver um melhor gerenciamento e controle de qualidade dos produtos. O controle de qualidade para os produtos de hortifrutigranjeiro deve ser específico, considerando a regulamentação de compra, a perecibilidade, a segurança e a vida de prateleira (RUBEN; BOSELIE; LU, 2007; PIGATTO, 2017). O aumento das perdas financeiras ocorridas no mês de junho/2017 foi devido o vencimento de ovos, somente nesse mês o valor monetário perdido com ovos foi de $R \$ 324.590,60$, o que representa aproximadamente $60 \%$ das perdas totais do ano na categoria: ovos.

Por meio da análise de Pareto foi analisado a maior porcentagem de perdas financeiras por mês em relação as frutas e hortaliças\&ovos. De acordo com os resultados, nota-se que em relação as frutas, durante o ano ocorreu uma variação entre maçã e banana, sendo que a maior porcentagem de perdas ocorreu no mês de fevereiro/2017 com a banana representando $21,51 \%$ das perdas, seguida pela maçã com perdas de 18,14\% ocorridas no mês de junho/2017. Já com relação a análise realizada com as hortaliças\&ovos, notou-se ocorreu uma variação de perdas entre tomate e ovos, sendo que o mês de junho apresentou a maior porcentagem de perdas de ovos com 49,05\%, Tabela 4.

Tabela 4 - Resumo da análise de Pareto aplicado por mês, por grupos

\begin{tabular}{lcccc}
\hline \multicolumn{1}{c}{ Mês } & Fruta & Valor (\%) & Hortaliça\&Ovos & Valor (\%) \\
\hline Janeiro & Maçã & 15,52 & Tomate & 14,98 \\
Fevereiro & Banana & 21,51 & Tomate & 15,53 \\
Março & Banana & 16,76 & Ovos & 15,05 \\
Abril & Banana & 15,71 & Tomate & 12,72 \\
Maio & Banana & 13,76 & Tomate & 14,06 \\
Junho & Maçã & 18,14 & Ovos & 49,05 \\
Julho & Maçã & 15,03 & Tomate & 13,57 \\
Setembro & Maçã & 17,70 & Tomate & 16,71 \\
Outubro & Maçã & 17,47 & Tomate & 11,84 \\
Novembro & Maça & 14,01 & Ovos & 11,80 \\
Dezembro & Banana & 10,65 & Ovos & 16,88
\end{tabular}

Fonte: Autores (2018) 
A distribuição física de alimentos perecíveis no Brasil segue o mesmo padrão que a distribuição física de cargas secas. Mesmo que as lojas planejem as quantidades de compra desses produtos, observa-se que o planejamento não é efetivo visto a quantidade de produtos que são devolvidos ao elo da cadeia anterior ou que se perde nas gôndolas dos supermercados. O planejamento deverá considerar a questão de perecibilidade de cada produto como um fator crucial e definição de lead time de reposição.

Como exemplo de sucesso, cita-se as lojas de conveniências japonesas, conhecidas como Konbinis, que oferecem diversos produtos aos seus clientes e estão espalhadas pelos centros urbanos e bairros do Japão (MARSHALL, 2016). Inicialmente, as lojas de conveniências faziam parte de uma cadeia voluntária conduzida por atacadistas e intermediários de produtos perecíveis, vegetais, frutas, carnes e peixes (MARSHALL, 2016).

Atualmente, as Konbinis oferecem praticidade para seus clientes com uma diversidade de produtos, se comportando como mini-mercados, pertencente ao setor varejista. De acordo com Marshall (2016) são 56.000 lojas de conveniências que representam $19 \%$ do total de vendas de alimentos e um valor de mercado de 10,2 trilhões de yen.

Segundo uma pesquisa realizada sobre a frequência de compra de alimentos dos consumidores, $22,5 \%$ afirmaram que compram alimentos frescos todos os dias nas lojas de conveniências (MARSHALL, 2018). Outros fatores apontados como importantes para o sucesso desse tipo de loja de conveniência, tem sido a localização estratégia, ou seja, perto de locais de trabalho, escolas, residências e transporte público, facilitando o acesso; o tempo de prestação de serviços (24 horas), preço baixo, diversidade de produtos, ofertas, alta qualidade, bom serviço, etc. (MARSHALL, 2018).

\section{Comparação do desperdício por grupo de produtos hortifrutigranjeiro}

A deterioração dos perecíveis é um dos principais agentes causadores das quebras operacionais do atacadista, evidenciando a necessidade de um melhor planejamento de compra e controle das datas de vencimentos dos produtos. $O$ gerenciamento da data de validade pode ser melhorado pela realização da ronda gôndola por funcionários, verificando os produtos com datas de validades mais curtas e os colocando a frente dos produtos com datas de validades mais longas. Além disso, quando os produtos apresentarem datas muito curtas de validades, o atacadista pode se utilizar das estratégias de promoção, baixando os preços dos produtos para incentivar a compra pelos consumidores, contudo de recomendação de consumo rápido; ou ainda, utilizar na produção de produtos da casa, para venda.

Os resultados apontam que aproximadamente $20 \%$ dos produtos correspondem a $60 \%$ das perdas por deterioração no setor de hortifrutigranjeiro, sendo os principais o tomate, ovos, maçã, cebola, banana, batata, alface, laranja, pimentão, mamão, manga, limão, mandioca e alho. A aplicação da qualidade na produção de alimentos é um critério importante pois determina o campo de comercialização e afeta o valor da produção (PANGHAL et al., 2018).

Considerando o tipo de perdas, observa-se que aproximadamente $91,5 \%$ das perdas foi por deterioração, seguida por vencimento $(7,5 \%)$, autorizada $(0,35 \%)$, transformação $(0,25 \%)$, funcionários $(0,17 \%)$, degustação $(0,12 \%)$ e cliente $(0,05 \%)$, desconsiderando as perdas por equipamento e fornecedores. 
O desperdício por deterioração de produtos, pode representar que os alimentos não estão chamando a atenção dos consumidores que os mantêm nas gôndolas até que haja a reposição por novos alimentos mais atrativos. Nesse sentido, recorda-se sobre os principais aspectos que são considerados pelos consumidores na escolha de seus produtos, principalmente, de frutas e verduras, tais como maturidade, tamanho, forma, color, odor, aparência, e a observação de danos na superfície dos alimentos (PANGHAL et al., 2018; MACHADO et al., 2017).

Uma alternativa para redução dessas perdas é o adequado gerenciamento da perecibilidade, ou seja, monitoramento dos produtos perecíveis e aqueles que se apresentam fora do padrão de comercialização, mas que ainda estão bons para o consumo humano, podem ser enviados para o processamento e aproveitamento na preparação de pratos pontos. Contudo, verifica-se que a comercialização e a logística de perecíveis ainda é um dos principais problemas a serem revolvidos, principalmente, nos países tropicais exigindo um esforço maior da cadeia produtiva para manter a segurança alimentar, por meio da qualidade de seus produtos. De acordo com os resultados, os grupos de hortaliças e frutas são os que mais contribuem com as perdas, com índices de perdas sobre vendas de 1,73\% e 1,23\%, Tabela 5.

\begin{tabular}{cccc}
\multicolumn{4}{c}{ Tabela 5 - Comparação entre perdas por grupo de alimento (valores monetários, em R $\$$ ) } \\
\hline Grupo & Frutas & Hortaliças & Ovos \\
\hline CL & $-535,64$ & $-956,45$ & $-360,81$ \\
EQ &. & $-63,80$ &. \\
FC & $-2.676,40$ & $-2.763,31$ & $-1.194,04$ \\
FO &. & - & $-4,08$ \\
DG & $-1.662,98$ & $-2.599,88$ & $-528,35$ \\
TR & $-307,96$ & $-7.592,44$ & $-1.945,92$ \\
DE & $-1.371 .244,00$ & $-1.938 .875,70$ & $-251.801,56$ \\
AUT & $-10.182,75$ & $-1.949,86$ & $-1.360,20$ \\
VE & $-2.237,89$ & $-5.426,59$ & $-287.413,18$ \\
Total & $-1.388 .847,62$ & $-1.960 .089,01$ & $-544.608,14$ \\
Índice sobre vendas\% & 1,23 & 1,73 & 0,48
\end{tabular}

Fonte: Autores (2018)

As frutas levam dias para atravessar a cadeia produtiva, por exemplo, desde a colheita no campo até a mesa do consumidor, e considerando suas características próprias de atividades metabólicas que continuam durante 0 transporte e armazenagem, contribui pouco para a rentabilidade do varejo (PANGHAL et al., 2018). Entre as dimensões de qualidade apresentadas por Garvin, a durabilidade como sendo a vida útil do produto, é muito difícil de se aplicar aos produtos agrícolas, devido as características próprias desses produtos de serem de curta duração (REIS; COSTA NETO, 2018). Considerando que a deterioração afeta diretamente algumas das dimensões de qualidade apontadas por Reis e Costa Neto (2018), tais como: desempenho do produto, conformidade dos produtos, confiabilidade, estética e qualidade percebida. Dessa forma, a gestão estratégica para garantir a integridade dos produtos de hortifrúti e reduzir as taxas de deterioração é importante para melhoria dos processos e redução das perdas, consequentemente, segurança alimentar e aumento de lucro.

Matopoulos et al. (2007), recomendam o entendimento do conceito de cadeia de suprimentos colaborativa analisando as particularidades da agroindústria, 
principalmente, devido as diversas mudanças ocorridas nos últimos tempos com a atitude de consumo dos consumidores mais conscientes que tem exigido a aplicação de regulamentação na produção, alterando o ambiente de negócio e atitudes colaborativas entre as empresas nos diferentes níveis da cadeia.

Um dos principais problemas no Brasil é a fragmentação da produção da agricultura familiar que não tem um direcionamento o que produzir, quando e quanto produzir, padrões de mercado e para quem produzir. Cada família produz o que conhece e o que acredita ser comercializável, mas desconhece os padrões de qualidade e não acompanha o desempenho do produto de mercado. De acordo com Ruben, Boselie e Lu (2007), a integração da cadeia de suprimentos é uma importante estratégia, para garantir o abastecimento de produtos hortifrúti frescos para os mercados na área urbana, atendendo os requisitos de alta frequência, entregas constantes e qualidade estável.

No quesito qualidade, Reis e Costa Neto (2018), afirmam que o produto é confiável quando está apropriado para o consumo, sem riscos à saúde do consumidor. Os autores vão além do conceito de qualidade aplicada ao produto e relatam que a qualidade logística está relacionada a disposição do produto no lugar certo e na quantidade certa (REIS; COSTA NETO, 2018).

\section{CONCLUSÕES}

Ao longo dos anos a perda de alimentos tem se tornado pautas discutidas com maior interesse, não somente pelo viés econômico como também pelo social. As perdas e desperdícios acontecem ao longo da cadeia produtiva, de diferentes maneiras em cada elo, sendo necessário diferentes abordagens estratégicas em cada ponto.

Neste estudo, o ponto de distribuição apresentou a deterioração como principal agente causador das perdas, deixando evidente a necessidade de um melhor planejamento de compra, maior controle da qualidade dos produtos adquiridos e melhoras nas formas de armazenagem e acondicionamento dos produtos, mantendo o frescor e as características organolépticas dos hortifrútis que fazem o consumidor adquirir o produto, evitando que fiquem um maior período nas gôndolas e sejam descartados posteriormente.

A qualidade dos produtos hortifrútis, seja in natura ou processados, depende do desenvolvimento e aplicação de métodos que atendam as características da cadeia da produtiva, garantindo a segurança alimentar e valor agregado aos produtos.

\section{Agradecimentos}

Agradecimento ao Instituo Federal de Educação, Ciência e Tecnologia, Câmpus Suzano, pela bolsa de Iniciação Científica (IC) concedida e a oportunidade de aprendizado na área da pesquisa. 


\section{REFERÊNCIAS}

ASSUNÇÃO, P. E. V.; WANDER, A. E. Competitividade do sistema agroindustrial do feijão-comum no Estado de Goiás. Scientia Plena, Sergipe, v. 10, n. 07, p1-12, 2014.

BELIK, W.; CUNHA, A. R. A. A.; COSTA, L. A. Crise dos alimentos e estratégias para a redução do desperdício no contexto de uma política de segurança alimentar e nutricional no Brasil. Planejamento e políticas públicas, Brasília, n. 38, p.107-132, 2012.

BRASIL. Agricultura familiar produz $70 \%$ dos alimentos consumidos por brasileiro. 2015. Disponível em: http://www.brasil.gov.br/economia-eemprego/2015/07/agricultura-familiar-produz-70-dos-alimentos-consumidos-porbrasileiro. Acesso em: 20 mar. 2018.

BUAINAIN, A.M.; BATALHA, M.O. Cadeia produtiva de frutas. Ministério da Agricultura, Pecuária e Abastecimento, Secretaria de Política Agrícola, Instituto Interamericano de Cooperação para a Agricultura. Brasília- DF. IICA: MAPA/SPA, 2007. $102 \mathrm{p}$.

CASTRO, J. A. O.; JAIMES, W. A. Dynamic Impact of the Structure of the Supply Chain of Perishable Foods on Logistics Performance and Food Security. Journal of Industrial Engineering and Management, Terrassa, v. 10. p. 687-710, 2017.

COMPANHIA DE ENTREPOSTOS E ARMAZÉNS GERAIS DE SÃO PAULO CEAGESP. Normas de classificação do tomate (lycopersicon esculentum Mill.). Programa Brasileiro para a Modernização da Horticultura, CEAGESP: São Paulo, 2003.

COMPANHIA DE ENTREPOSTOS E ARMAZÉNS GERAIS DE SÃO PAULO. Banco CEAGESP de Alimentos, 201AD. Disponível em: http://www.ceagesp.gov.br/aceagesp/sustentabilidade/responsabilidade-social/bca/. Acesso em: 20 maio. 2017

CONFEDERAÇÃO DA AGRICULTURA E PECUÁRIA NO BRASIL. Mapeamento e quantificação da cadeia produtiva das hortaliças do Brasil. Confederação da agricultura e pecuária no Brasil. Brasília, DF. CNA. 2017. 79p.

CREFITO. Diferenças entre associações e cooperativas. 2010. Disponível em: https://www.crefito8.gov.br/pr/index.php/associacoes-e-cooperativas/129servicos/associacoes-e-cooperativas/477-diferencas-associacoes-e-cooperativas Acesso em: 18 nov. 2018.

COUNCIL OF SUPPLY CHAIN MANAGEMENT PROFESSIONALS. SCM_Definitions_and_Glossary_of_Terms. Disponível em: https://cscmp.org/CSCMP/Educate/SCM Definitions and Glossary of Terms.aspx. Acesso em: 18 nov. 2018.

DONATO, D.C.Z.; GANDRA, E.R.S.; GARCIA, P.D.; REIS, C.B.; GAMEIRO, A.H. A A questão da qualidade no sistema agroindustrial do ovo. In: 47을 CONGRESSO DA SOCIEDADE BRASILEIRA DE ECONOMIA, ADMINISTRAÇÃO E SOCIOLOGIA 
RURAL, 2009, Porto Alegre-RS. Anais... Porto Alegre: SOBER, 2009, p.1-13.

Disponível em http://paineira.usp.br/lae/wp-

content/uploads/2017/02/2009 Donato Gandra.pdf. Acesso em: 18 nov. 2018.

EMPRESA BRASILEIRA DE PESQUISA AGROPECUÁRIA. 2016. Disponível em: https://www.embrapa.br/ Acesso em: 10 abr. 2018.

FIGUEIREDO, K.; GOLDSMID, I.K.; ARKADER, R. HIJJAR, F. Segmentação logística: um estudo na relação entre fornecedores e varejistas no Brasil. RAC, Maringá, v. 11, n. 4, p.11-31, 2007.

FOOD AND AGRICULTURE ORGANIZATION OF THE UNITED NATIONS (FAO UN). Crops, 2014. Disponível em: http://www.fao.org/faostat/en/\#data/QC. Acesso em: 13 maio. 2018

FOOD AND AGRICULTURE ORGANIZATION OF THE UNITED NATIONS (FAO UN).. Citrus fruit statistics, 2015. Disponível em: www.fao.org/publications. Acesso em: 13 maio. 2018

FOOD AND AGRICULTURE ORGANIZATION OF THE UNITED NATIONS (FAO UN). ONU anuncia o lançamento do primeiro padrão global para medir perda e desperdício de alimentos. 2016. Disponível em: https://nacoesunidas.org/onuanuncia-o-lancamento-do-primeiro-padrao-global-para-medir-perda-e-desperdiciode-alimentos. Acesso em: 5 jun. 2018.

FOOD AND AGRICULTURE ORGANIZATION OF THE UNITED NATIONS (FAO UN). Organização das Nações Unidas para a alimentação e a agricultura. 2017. Disponível em: https://nacoesunidas.org/fao-30-de-toda-a-comida-produzida-nomundo-vai-parar-no-lixo.

/ Acesso em: 15 mai. 2018.

FOODDRINK EUROPE. What is food wastage? Disponível em: https://www.fooddrinkeurope.eu/our-actions/foodwaste-toolkit/what-is-food-wastage.

Acesso em: 15 mai. 2018.

FOSCACHES, C. A. L., S. R. L. QUEVEDO-SILVA, F., LIMA-FILHO, D. O. Logística de frutas, legumes e verduras (FLV): um estudo sobre embalagem, armazenamento e transporte em pequenas cidades brasileiras. Informações Econômicas, v. 42, p. 3746, 2012.

GLORIA, V. R. C.; PRIOR, M. V. F.; MARJOTTA-MAISTRO, M. C. Análise da logística de produtos perecíveis: o caso da maçã. Economias Agrária e dos Recursos Naturais. In: JNIC/SBPC, 2015, São Carlos. Anais...São Carlos: 67ํ Reunião Anual da SBPC, 2015. 
HSIEN, H. W. Atacado e atacarejo como opção de compra de clientes de distribuidora de alimentos. Revista de Administração da Universidade Federal de Santa Maria, Santa Maria, v. 5, n. 1, p. 11-28, 2012.

LIMA, E.A.S. et al. Riscos logísticos na distribuição de hortifrúti. Gestão e Desenvolvimento, Novo Hamburgo, v. 14, n. 1, P.114-127, 2017.

LINS, J. H. T. et al. Logística de hortifrútis - um estudo de caso sobre a cadeia de suprimentos de frutas, legumes e verduras em uma filial de atacarejo da cidade de Juazeiro do Norte - CE. In: CONGRESSO LATINO AMERICANO DE ADMINISTRAÇÃO E NEGÓCIOS, 2017, Ponta Grossa. Anais...Ponta Grossa: CONLAAN, 2017.

MINISTÉRIO DA AGRICULTURA, PECUÁRIA E ABASTECIMENTO. Cooperativismo e Associativismo no Brasil. 2016. Disponível em: http://www.agricultura.gov.br/assuntos/cooperativismoassociativismo/cooperativismo-brasil Acesso em: 25 jun. 2018.

MARSHALL, D. Convenience stores and discretionary food consumption among Young Tokyo consumers. International Journal of Retail \& Distribution Management, West Yorkshire, v. 44, n.10, p. 1013-1029, 2016.

MARSHALL, D. Convenience stores and well-being of young Japanese consumers. International Journal of Retail \& Distribution Management, West Yorkshire, https://doi.org/10.1108/IJRDM-08-2017-0182, 2018.

MATOPOULOS, A.; VLACHOPOULOU, M.; MANTHOU, V. A conceptual framework for supply chain collaboration: empirical evidence from the agri-food industry. Supply Chain Management: An International Journal, West Yorkshire, v. 12, n.3, p. 177-186, 2007.

OLIVEIRA, Vanderley de. Manual: Sistemas Agro Industriais, 2011, p.21.

OLIVEIRA, L. D. S.; LIMA-FILHO, D. O.; WATANABE, E. A. M. Nível de Desenvolvimento e Tecnologia de Distribuição de Alimentos em Países Selecionados. RESR, Piracicaba-SP, v. 51, n.1, p. 09-24, 2013.

PANGHAL, A. ; YADAL, D.; KHATKAR, B.S.; Sharma, H.; KUMAR, V.; CHHIKARA, N. . Post-harvest malpractices in fresh fruits and vegetables: food safety and health issues in India. Nutrition \& Food Science, West Yorkshire, v. 48, n. 4, p.561-578, 2018. Disponível em: https://www.semanticscholar.org/paper/Post-harvestmalpractices-in-fresh-fruits-and-food-PanghalYadav/e96d3ac14fe8bdb4982ff8532d28d67b32bd6480. Acesso em 15 mai. 2018.

PIGATTO, G. Cadeia de suprimentos de perecíveis: como restaurantes selecionam e se relacionam com fornecedores de hortaliças. Economia \& Região, Londrina (Pr), v.5, n.1, p.7-30, jan./jun. 2017. 
REIS, J.G.M et al. Reducing food losses and food wastes in distribution and retail centers: A case study of Brazilian CEAGESP. In: GLOBAL FOOD SECURITY CONFERENCE, 2015 Ithaca. Anais...Ithaca: GLOBAL, 2015.

REIS, J.G.M.; COSTA NETO, P.L.O. Qualidade aplicada ao agronegócio. In: REIS, J.G.M.; COSTA NETO, P.L.O. Engenharia de Produção Aplicada ao agronegócio, São Paulo: Blucher, 2018, p. 312.

RUBEN, R.; BOSELIE, D.; LU, H. Vegetables procurement by Asian supermarkets: a transaction cost approach. Supply Chain Management: An international Journal, West Yorkshire, v. 12, n. 1, p. 60-68, 2007.

SELLA, M. R.; SILVA, E. C. C. Avaliação do desempenho da logística de distribuição de alimentos perecíveis: o estudo dos fatores que influenciam na eficiência da fruticultura no segmento supermercadista. In: III SEMINÁRIO FRANCO-BRASILEIRO TRANSFORMARE, 2012, Piracicaba. Anais... Piracicaba: TRANSFORMARE, 2012.

SERVIÇO BRASILEIRO DE APOIO ÀS MICRO E PEQUENAS EMPRESAS (SEBRAE). Guia de Indicadores aplicados ao varejo. Disponível em: https://m.sebrae.com.br/Sebrae/Portal\%20Sebrae/Anexos/Download/Guia_de_Indica dores_para_Varejo.pdf. Acesso em: 15 mai. 2019.

VIAL, L.A.M. et al. Arranjos produtivos locais e cadeias agro-alimentares: revisão conceitual. Gestão da Produção, Operações e Sistemas, Bauru, Ano 4, no 3, p. 105121, 2009. 